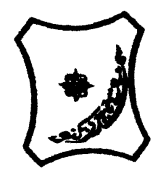

Bayero Journal of Pure and Applied Sciences, 9(1): 228 - 235

Received: June, 2015

Accepted: December, 2015

ISSN $2006-6996$

\title{
EVALUATION OF ANTI-INFLAMMATORY, ANTIBACTERIAL AND CYTOTOXIC ACTIVITIES OF Cordia africana LEAF AND STEM BARK EXTRACTS
}

\author{
${ }^{*}$ Isa, Adamu Imam1 ${ }^{1}$, Saleh, Malajiya Ibrahim Alhaji ${ }^{1}$, Abubakar, Ahmad ${ }^{2}$,Dzoyem, Jean \\ Paul $^{3}$., Adebayo, Salman Adeniyi ${ }^{4}$., Musa, Idris ${ }^{1}$., Sani Usman Fulatan ${ }^{1}$ and Daru Peret \\ Alexandra ${ }^{1}$
}

${ }^{1}$ Department of Human Physiology, Faculty of Medicine, Ahmadu Bello University, Zaria, Nigeria. ${ }^{2}$ Department of pharmacognosy and drug development, Faculty of Pharmaceutical Sciences, Ahmadu Bello University, Zaria, Nigeria ${ }^{3}$ Department of Biochemistry, Faculty of Science, University of Dschang, P.O. Box 67, Dschang, Cameroon ${ }^{3}$ Faculty of Science, Department of Biomedical Sciences, Tshwane University of Technology, Private Bag X680, Pretoria, 0001, South Africa.

Corresponding author: +2348035867084, adamuisaimam@gmail.com

\section{ABSTRACT}

Cordia africana (Boraginaceae) is a tree used in traditional medicine to treat inflammation related conditions and infectious diseases. This study was undertaken with the objectives of establishing the scavenging effect of extracts and fractions of Codia africana on the mediator of inflammation Lipoxygenases (LOX), and some non-biological free radicals such as 2,2-diphenyl-1-picrylhydrazyl (DPPH), the [2, 2-azinobis (3-ethylbenzothiazoline-6-sulfonic acid)] (ABTS) radicals and the Ferric ion reducing antioxidant power (FRAP). Antimicrobial activities, total phenolics/flavonoids and cytotoxicity of extracts of Codia africana were also evaluated. Extracts were obtained by maceration. Anti-inflammatory activity was determined using a LOX-inhibitor screening assay kit according to the manufacturer's instructions. A broth serial micro dilution method was used to determine the minimum inhibitory concentration (MIC) against, Gram-positive and Gram-negative bacteria and Mycobacterium species. The antioxidant activity was determined using free-radical-scavenging assays, and the 3-(4,5dimethylthiazolyl-2)-2,5- diphenyltetrazolium bromide reduction assay was used for cytotoxicity. Both the extracts of $C$. africana inhibited LOX enzyme. The most active being the methanol extract of the bark with $I C_{50}$ value of $55 \pm 0.9 \mu \mathrm{g} / \mathrm{ml}$. Both the extracts of C. africana, had excellent to weak antimicrobial activites (MICs ranging from 32 to $1024 \mu \mathrm{g} / \mathrm{ml}$ ) against bacteria. All the extracts had significant $(P<0.05)$ free-radical scavenging activity (IC 50 ranging from $6.79 \pm 0.07$ to $331.98 \pm 0.07$ $\mu \mathrm{g} / \mathrm{ml})$. There was a positive correlation between the antioxidant activity and the total flavonoid and total phenolic contents of Cordia africana. The cytotoxicity on Vero cells was low with $L C_{50}$ of $81.79 \pm$ 13.31 and $99.67 \pm 16.10 \mu \mathrm{g} / \mathrm{ml}$. The results support the use of $C$. africana leaves in traditional medicine to treat inflammation related conditions and infectious diseases.

Keywords: Cordia Africana, Inflammation, antibacterial, antioxidant, total flavonoid.

\section{INTRODUCTION}

Cordia africana is a small to medium-sized evergreen tree, 4-15 (30) m high, heavily branched with a spreading, umbrella-shaped or rounded crown. Bole typically curved or crooked. It is widely distributed in eastern and southern Africa. In West Africa, this species is restricted to montane and submontane habitats (Schmidt and Mwaura, 2010). The pharmacological studies carried out with extracts and purified compounds indicates that the plants of Cordia species possess analgesic, anti-inflammatory, antimicrobial, antiviral and antifertility activities. Various compounds like flavonoids, triterpenes, tannins, alkaloids and fatty acids possessing wide range of bioactivities were isolated from different plant parts of Cordia species (Thirupathi et al., 2008). Based on these reports it is clearly indicated that the plants of Cordia genus possess potential therapeutic actions. Cordia africana is used traditionally to treat stomach ache, toothache, wound and cough (Reta, 2013).
It is well known that reactive oxygen species (ROS), such as superoxide anion (O2•-), hydroxyl radicals $(\mathrm{OH} \bullet)$, singlet oxygen $\left({ }^{1} \mathrm{O}_{2}\right)$ and hydrogen peroxide $\left(\mathrm{H}_{2} \mathrm{O}_{2}\right)$, play a major role in the development of oxidative stress that can lead to many illnesses including cardiovascular diseases, diabetes, inflammation, degenerative diseases, cancer, anemia, and ischemia (Cai et al., 2004). Plant based antioxidant compounds play a defensive role by preventing the generation of free radicals and hence are extremely beneficial to alleviate the diseases caused by oxidative stress (Akinmoladun et al., 2010; Özen et al., 2010). Many investigations revealed that phenolics and flavonoids content (Cai et al., 2004; Hendra et al., 2011) contribute to the antioxidant activities of plants. The anti-inflammatory properties of flavonoids have been extensively studied and beneficial effects have been demonstrated in many animal models (Talhouk et al., 2007). 
Bajopas Volume 9 Number 1 June, 2016

15-Lipoxygenase (15-LOX) belongs to the class of iron containing Lipoxygenases that catalyse the incorporation of dioxygen into unsaturated fatty acid (Feussner and Wasternack, 2002). Lipoxygenases are the key enzymes in the biosynthesis of leukotrienes that play an important role In several inflammatory diseases (Funk, 2006). Inflammation is one of the manifestations of oxidative stress, and the pathways that generate the mediators of inflammation, such as adhesion molecules and interleukins, are all induced by oxidative stress (Mehta et al., 2006). Inhibition of LOX may influence the inflammation processes and thus be of interest for modulation of the lipoxygenase pathway. Therefore, inhibitors of oxidative stress and LOX have been considered as therapeutically useful in the treatment of many related diseases (Sommer, 2005). The objectives of this work therefore is to establish the scavenging effect of extracts and fractions of Codia africana on the mediator of inflammation lipoxygenases (LOX), and some non-biological free radicals such as 2,2-diphenyl1-picrylhydrazyl (DPPH), the $[2,2$-azinobis (3ethylbenzothiazoline-6-sulfonic acid)] (ABTS) radicals and the Ferric ion reducing antioxidant power (FRAP). Antimicrobial activities, total phenolics/flavonoids and cytotoxicity of extracts of Codia africana were also evaluated.

\section{MATERIALS AND METHODS}

\section{Plant material and extraction}

Cordia africana was collected in January, 2014 in Bomo village, Zaria, Nigeria. The plant was identified and authenticated by a taxonomist, in the Herbarium section, Department of Biological Sciences, Ahmadu Bello University, Zaria as compared by a voucher specimen No. 900161. The collected plant material was dried at room temperature and ground using MacSalab Model 200 grinder. The powder obtained $(100 \mathrm{~g})$ was extracted successively with methanol $(250 \mathrm{ml})$, and hexane $(250 \mathrm{ml})$ using soxhlet extractor. It was then concentrated under reduced pressure using a rotary evaporator to obtain the crude extract. The crude extracts were kept at $4{ }^{\circ} \mathrm{C}$ prior to use.

\section{Chemicals}

Sodium carbonate was obtained from Holpro Analytic, South Africa. Gentamicin was purchased from Virbac, South Africa. Fetal calf serum (FCS) and minimum essential medium (MEM with L-glutamine) was provided by Highveld Biological, Johannesburg, South Africa. Phosphate buffered saline (PBS) and trypsin were purchased from White head Scientific, South Africa. Doxorubicin was obtained from Pfizer.Quercetin, 2,20azino-bis (3-ethylben-zothiazoline-6-sulfonic acid) diammonium salt (ABTS), 2,2-diphe-nyl-1-picrylhydrazyl (DPPH), 3-(4,5-dimethylthiazol-2-yl)-2,5diphenyltetrazoliumbromide (MTT), p-iodonitro tetrazolium violet (INT), Folin-Ciocalteu reagent, gallic acid, 2,5,7,8-tetramethylchroman carboxylic acid (Trolox) and potassium persulfate were purchased from Sigma-Aldrich St.Louis, MO, USA. Sodium dodecyl sulfate, potassium ferric cyanide, iron(II) sulphate from Glycine max were provided by Sigma, Germany. Tris (hydroxy- methyl) amino methane was purchased from
Sigma, Switzerland. Ferric chloride and linoleic acid were purchased from Merck, Darmstadt and Schuchardt, Germany respectively, Xylenol orange was obtained from Searle Company, England. LOX-inhibitor screening assay kit (Catalog No. ab133087) was obtained from abcam, UK.

\section{Lipoxygenase inhibition assay}

The anti-inflammatory activities of extract from the bark of Cordia africana were evaluated for LOX inhibitory activity using a LOX-inhibitor screening assay kit (Catalog No. ab133087, abcam, UK) according to the manufacturer's instructions. This assay detects and measures the hydroperoxides produced in the lipoxygenation reaction using a purified Lipoxygenases. Briefly, the stock solution of the extract was dissolved in methanol and serially diluted two-fold to concentration ranges between 5 to $0.08 \mathrm{mg} \mathrm{mg} / \mathrm{mL}$ for both extracts and the standard reference (aspirin) and then introduced in a 96 well microtitre plate. The wells include the blank, 15-LOX standard, $100 \%$ initial activity and the inhibitor wells. One hundred microliter of assay buffer, $90 \mu \mathrm{L}$ of 15 -LOX enzyme and $10 \mu \mathrm{L}$ of Assay Buffer, $90 \mu \mathrm{L}$ of LOX enzyme and $10 \mu \mathrm{L}$ solvent and $90 \mu \mathrm{L}$ of LOX enzyme and $10 \mu \mathrm{L}$ of extract were added in the wells respectively. The reaction was initiated by addition of $10 \mu \mathrm{L}$ of substrate (arachidonic acid) to all the wells and incubated at room temperature for $5 \mathrm{~min}$ on a shaker. After the $5 \mathrm{~min}$ incubation, $10 \mu \mathrm{L}$ of chromogen was added to each well to stop enzyme catalysis and developed the reaction. The microtiter plate was covered and further incubated at room temperature for 5 min on a shaker. The cover was removed and the absorbance was immediately read at the wavelength of $500 \mathrm{~nm}$ using a micro plate reader. Percentage inhibition was calculated using the following equation.

Percentage Inhibition $=$

$$
\left\{\frac{1 A-\text { mhibitor }}{I A}\right\} \times 100 \%
$$

Where IA is initial activity

The concentration at which there was $50 \%$ enzyme inhibition $\left(\mathrm{IC}_{50}\right)$ was determined by graphing the percent inhibition or percent initial activity against the extract concentration.

\section{ANTIOXIDANT ACTIVITY [2, 2-azinobis (3-ethylbenzothiazoline-6-sulfonic acid)] radical assay}

The ABTS radical scavenging capacity of the samples was measured with modifications of the 96-well microtitreplate method described by $\mathrm{Re}$ et al.(1999). Trolox and ascorbic acid were used as positive controls methanol as negative control and extract without ABTS as blank. 
The percentage of ABTS $\bullet+$ inhibition was calculated using the formula: Scavenging capacity $(\%)=$ Radical scavenging

$$
=100-\left(\frac{\text { Absample }- \text { Abblank })}{\text { Abcontrol }}\right) \times 100
$$

Where $A b_{\text {sample }}$ is the absorbance of the extract with $\mathrm{DPPH}, A b_{\text {blank }}$ is the absorbance of the extract without $\mathrm{DPPH}$ and $A b_{\text {control }}$ is absorbance of methanol and DPPH. The $\mathrm{IC}_{50}$ values were calculated from the graph plotted as inhibition percentage against the concentration.

\section{2,2-diphenyl-1-picrylhydrazyl (DPPH) assay}

The DPPH radical-scavenging activity was determined using the method proposed by Brand-Williams et al. (1995). Ascorbic acid and Trolox were used as positive controls, methanol as negative control and extract without DPPH as blank. Results were expressed as percentage reduction of the initial DPPH absorption in relation to the control. The concentration of extract that reduced the DPPH color by $50 \%\left(\mathrm{IC}_{50}\right)$ was determined as for $\mathrm{ABTS} \bullet+$.

\section{Ferric reducing antioxidant power (FRAP) assay} The FRAP of samples was determined by direct reduction of potassium ferricyanide $\left(\mathrm{K}_{3} \mathrm{Fe}(\mathrm{CN})_{6}\right)$ to potassium ferrocyanide $\left(\mathrm{K}_{4} \mathrm{Fe}(\mathrm{CN})_{6}\right)$ (electron transfer process from the antioxidant). The increase in absorbance from the formation of Pearl's Prussian blue complex following the addition of excess ferricion was measured as described by Berker et al. (2007) with some modification. The reaction medium $(210 \mathrm{~mL})$ containing $40 \mathrm{~mL}$ of the test samples or positive controls (Trolox and ascorbic acid; concentration range between: 15.62 and $2000 \mathrm{mg} / \mathrm{mL}$ ) and $100 \mathrm{~mL}$ of $1.0 \mathrm{M}$ hydrochloric acid; $20 \mathrm{~mL}$ of $1 \%(\mathrm{w} / \mathrm{v})$ of SDS; $30 \mathrm{~mL}$ of $1 \%(\mathrm{w} / \mathrm{v})$ of potassium ferricyanide, was incubated for $20 \mathrm{~min}$ at $50{ }^{\circ} \mathrm{C}$, then cooled to room temperature. Finally, $20 \mathrm{~mL}$ of $0.1 \%(\mathrm{w} / \mathrm{v})$ of ferric chloride was added. The absorbance at $750 \mathrm{~nm}$ was read and reagent blank absorbance was taken by preparing the reaction medium the same way without the addition of ferric chloride. The Trolox Equivalent Antioxidant capacity (TEAC) was calculated by dividing the slope of each sample (slope obtained from the line of best fit of the absorbance against concentration using the linear regression curve) by that of trolox.

\section{Total phenolic content (TPC) determination}

The total phenolic content of extracts was determined colorimetrically using a 96-well microplate FolinCiocalteu assay developed by Zhang et al. (2006). The total phenolic content was calculated from the lineare quation of a standard curve prepared with galli cacid, and expressed as gallic acid equivalent (GAE) per $g$ of extract.

\section{Total flavonoids content (TFC) determination}

Total flavonoid content was determined using the method of Ordonez et al. (2006). Avolume of $0.5 \mathrm{~mL}$ of $2 \% \mathrm{AlCl}_{3}$ ethanol solution was added to $0.5 \mathrm{~mL}$ of sample solution $(1 \mathrm{mg} / \mathrm{mL})$. After one hour at room temperature, the absorbance was measured at $420 \mathrm{~nm}$. Ayellow color is indicative of the presence of flavonoids. Total flavonoid content was calculated and expressed as mg quarcetin equivalent/g of crude extract using a standard curve prepared with quercetin.

\section{ANTIMYCOBACTERIAL ACTIVITY ASSAY Microbial culture}

Mycobacterium smegmatis (ATCC1441), Mycobacterium aurum (NCTC 10437) and Mycobacterium fortuitum (ATCC6841) were cultured as described by McGaw et al (2008). They were maintained on Middle brook 7H10 agar slants, supplemented with glycerol or tween 20. Inocula suspensions were prepared by mixing a few microbial colonies with sterile distilled water. The suspension was diluted with sterile water to render a concentration of cells equal to standard Mc Farland1 standard solution (approximately $4 \times 10^{7} \mathrm{cfu} / \mathrm{mL}$ ), and then diluted with freshly prepared Middle brook $7 \mathrm{H} 9$ broth supplemented with $10 \%$ oleic albumin dextrose catalase (OADC) to obtain a final inoculum density of approximately $4 \times 10^{5} \mathrm{cfu} / \mathrm{mL}$.

Four Gram-positive bacteria, Bacillius cereus (ATCC 14579), Staphylococcus aureus (ATCC 29213) and Enterococcus faecalis (ATCC 29212), two Gramnegative bacteria, Pseudomonas aeruginosa (ATCC 25922) Salmonella typhimurium (ATCC 700720). Bacterial culture was taken from $24 \mathrm{~h}$ fresh agar culture plates and inoculated in fresh Mueller-Hinton broth (MHB) (Fluka, Switzerland), prior to conducting the assay. The turbidity of the microbial suspension was adjusted to a McFarland standard 0.5 equivalent to concentrations of $1-5 \times 10^{8} \mathrm{cfu} / \mathrm{ml}$. The microbial suspensions were further diluted $(1: 100)$ in media to obtain a final inoculum of approximately $1.5 \times 10^{6}$ $\mathrm{cfu} / \mathrm{ml}$.

\section{Determination of minimum inhibitory and bactericidal concentration (MIC)}

The broth microdilution technique using 96-well microplates, as described by Eloff (1998) was used to obtain the MIC and MBC values of Cordia africana samples. Extracts $(100 \mathrm{~mL})$ at an initial concentration of 10 $\mathrm{mg} / \mathrm{mL}$ were serially diluted, two-fold in 96-well microtitre plates, with equal volumes of Middle brook 7H9 broth. Then, $100 \mathrm{~mL}$ of inocula were added to each well to give a final concentration range of 2.5-0.019 $\mathrm{mg} / \mathrm{mL}$. The plates were incubated overnight for Mycobacterium smegmatis, Bacillius cereus, Staphylococcus aureus, Enterococcus faecalis, Pseudomonas aeruginosa, Salmonella typhimurium and 3 days for Mycobacterium aurum and Mycobacterium fortuitum at $37{ }^{\circ} \mathrm{C}$. To indicate bacterial growth, $40 \mathrm{~mL}$ of $0.2 \mathrm{mg} / \mathrm{mL}$ INT was added to each well after incubation and the plates incubated further at $37{ }^{\circ} \mathrm{C}$ for 1h. The MIC was defined as the lowest concentration that inhibited the color change of INT (yellow to purple). The experiment was performed in triplicate.

\section{CYTOTOXIC TEST}

The cytotoxicity of the extracts (dissolved in acetone) against Vero monkey kidney cells was assessed by the MTT reduction assay as previously described by Mosmann (1983) with slight modifications. Cells were seeded at a density of $1 \times 10^{5}$ cells $/ \mathrm{ml}(100 \mu \mathrm{l})$ in96well microtitre plates and incubated at $37{ }^{\circ} \mathrm{C}$ and $5 \%$ $\mathrm{CO}_{2}$ in a humidified environment. 
After $24 \mathrm{hrs}$ incubation, extracts $(100 \mathrm{ml})$ at varying final concentrations were added to the wells containing cells. Doxorubicin was used as a positive reference. A suitable blank control with equivalent concentrations of acetone was also included and the plates were further incubated for $48 \mathrm{~h}$ in a $\mathrm{CO}_{2}$ incubator. Thereafter, the medium in each well was aspirated from the cells, which were then washed with PBS, and finally fresh medium ( $200 \mathrm{ml}$ ) was added to each well. Then, $30 \mathrm{ml}$ of MTT $(5 \mathrm{mg} / \mathrm{ml}$ in phosphate buffered saline (PBS)) was added to each well and the plates were incubated at $37{ }^{\circ} \mathrm{C}$ for $4 \mathrm{~h}$. The medium was aspirated from the wells and dimethyl sulphoxide (DMSO) was added to solubilize the formed formazan crystals. The absorbance was measured on aBioTek Synergy microplate reader at $570 \mathrm{~nm}$. The percentage of cell growth inhibition was calculated based on a comparison with untreated cells. The selectivity index values were calculated by dividing cytotoxicity LC $_{50}$ values by the MIC values in the same units $\left(\mathrm{SI}=\mathrm{LC}_{50} / \mathrm{MIC}\right)$.

\section{STATISTICAL ANALYSIS}

All experiments were conducted in triplicate and values expressed as mean \pm standard deviation. Statistical analysis was performed using statistical package for social sciences (SPSS). One way analysis of variance (ANOVA) was used to compare means and results were compared using Fisher's least significant difference (LSD) at a $5 \%$ significance level.

\section{RESULTS}

DPPH, ABTS, FRAP, total phenolics (TPC) flavonoids content (TFC)

Table 1 shows DPPH, ABTS, FRAP, total phenolics (TPC) flavonoids content (TFC) of $C$. Africana. The free radical scavenging ability has been determined by using several different assays (Table1). There was a very good correlation between DPPH and ABTS values $\left(R^{2} 0\right.$. .826) and between TPC and TFC $\left(R^{2} 0.956\right)$ of the different extracts. There was significant $(P<0.05)$ antioxidant activity in both extracts though lower than the standards (ascorbic acid and trolox) in all cases. Results varied depending on the method used. In both the DPPH and ABTS assays, the methanol extract of the bark of $C$. africana had the highest antioxidant activity with IC $_{50}$ values of $6.79 \mu \mathrm{g} / \mathrm{mL}$ and $12.42 \mu \mathrm{g} / \mathrm{mL}$ respectively. The trend for FRAP activities of the extracts tested, did not markedly differ from their DPPH and ABTS scavenging activities; TEAC values obtained were 12.93 from the hexane extract of the leave and 93.84 from the methanol extract of the bark. Results in Table1 also indicate the TPC and TFC of the extracts analysed as milligram of gallic acid equivalent per gram of extract and milligram quercetin equivalent per gram of extract respectively. The methanol extract (bark) had the highest phenolic and flavonoid content (43.71 $\mathrm{mgGAE} / \mathrm{g}$ and $3.91 \mathrm{mgQE} / \mathrm{g}$ respectively). The hexane extract of the leave of $C$. africana with the lowest antioxidant activity in the DPPH and ABTS assays also had the lowest phenolic and flavonoid contents (2.56 $\mathrm{mgGAE} / \mathrm{g}$ and $2.75 \mathrm{mgQE} / \mathrm{g}$ respectively). Results in Table2 indicate the Pearson's correlation between the total phenolic and total flavonoids content and antioxidant activity, a statistically significant relationship was observed between TPC, TFC and FRAP.

Table 1: Antioxidant activity, total phenolic and total flavonoid contents of extracts from hexane leave and methanol bark of Cordia africana

\begin{tabular}{|c|c|c|c|c|c|}
\hline Extract & $\begin{array}{l}\text { ABTS IC } \text { SD0 } \\
(\mu \mathrm{g} / \mathrm{ml})\end{array}$ & $\begin{array}{l}\text { DPPH IC }_{50} \\
(\mu \mathrm{g} / \mathrm{ml})\end{array}$ & FRAB (TEAC) & $\begin{array}{l}\text { TPC (mg } \\
\text { GAE/g) }\end{array}$ & $\begin{array}{l}\text { TFC (mg } \\
\text { QE/g) }\end{array}$ \\
\hline $\mathrm{CHL}$ & $331.98 \pm 0.07^{a}$ & $315.86 \pm 0.07^{a}$ & $12.93 \pm 0.07^{b}$ & $2.56 \pm 0.07^{i}$ & $2.75 \pm 0.07^{i}$ \\
\hline CMB & $12.42 \pm 0.07^{b}$ & $6.79 \pm 0.07^{d}$ & $93.84 \pm 0.07^{c}$ & $43.71 \pm 0.07^{j}$ & $3.91 \pm 0.07^{k}$ \\
\hline TRO & $7.24 \pm 0.07^{e}$ & $3.26 \pm 0.07^{f}$ & $1.00 \pm 0.00^{\mathrm{g}}$ & nd & nd \\
\hline Ascorbic acid & $3.97 \pm 0.07^{f}$ & $1.41 \pm 0.18^{\mathrm{g}}$ & $2.92 \pm 0.04^{h}$ & nd & nd \\
\hline
\end{tabular}

Values with different letters are significantly different at $p<0.05$.

Table 2: Coefficient of correlation $r^{2}$ and Pearson's correlation coefficients of antioxidant activity (DPPH, FRAP, ABTS), total polyphenol content (TPC) and total flavonoid (TFC) of extracts from hexane leave and methanol bark of Cordia africana

\begin{tabular}{lllllll}
\hline & & ABTS & DPPH & FRAP & TPC & TFC \\
\hline$r^{2}$ & ABTS & 1 & .826 & -.889 & -.644 & -.326 \\
$p$ & & .022 & .007 & .118 & .475 \\
$r^{2}$ & DPPH & & 1 & -.828 & -.654 & -.371 \\
$p$ & & & .022 & .111 & .413 \\
$r^{2}$ & FRAP & & & 1 & .676 & .348 \\
$p$ & & & & .095 & .444 \\
$r^{2}$ & TPC & & & & 1 & -.026 \\
$p^{2}$ & & & & & & .956 \\
\hline
\end{tabular}

There is a significant correlation between pairs of variables with $p<0.05$. 


\section{5-Lipoxygenase inhibitory activity}

The results presented in Fig. 1 show that both the extracts investigated had a certain level of 15 -lipoxygenase inhibitory effect. The methanol extract of the bark had the highest inhibitory activity of $70.45 \%$ of 15 -lipoxygenase inhibition. Table 3 shows the $\mathrm{IC}_{50}$ values. The methanol extract of the bark had the highest $\mathrm{IC}_{50}$ value of $55 \pm 0.98$ $\mu \mathrm{g} / \mathrm{mL}$.

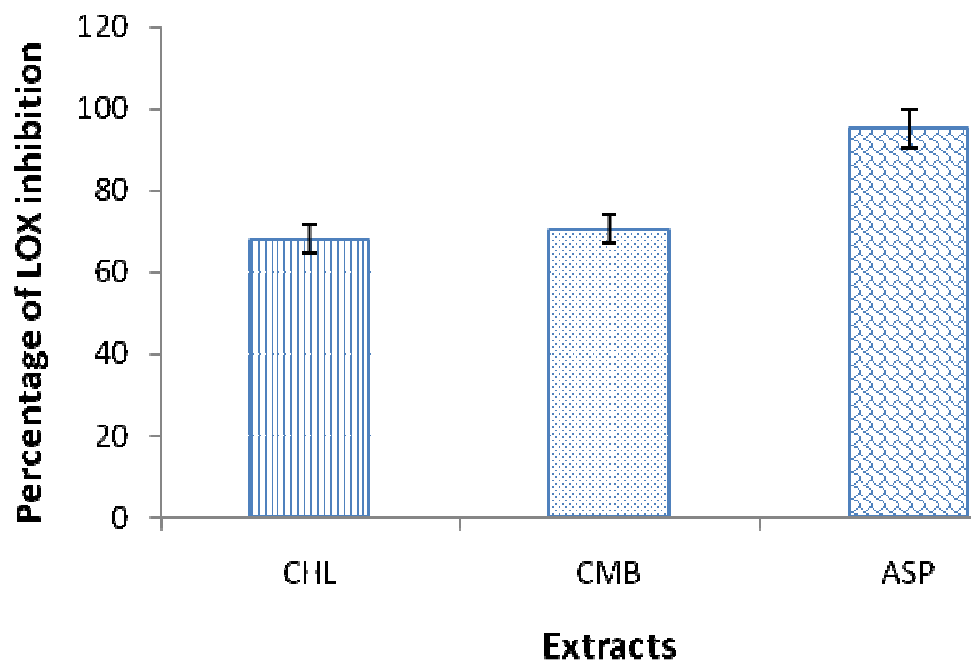

Figure 1: 15-Lipoxygenase inhibitory activity of extracts from hexane leave and methanol bark of Cordia africana. Extracts were tested at $(5 \mathrm{mg} / \mathrm{ml})$.

Table 3: $\mathrm{IC}_{50}$ of extracts from hexane leave and methanol bark of Cordia africana

\begin{tabular}{lc}
\hline Extracts & $\left.\mathbf{I C}_{\mathbf{5 0}} \mathbf{(} \boldsymbol{\mu g} / \mathbf{m l}\right)$ \\
\hline Asp & $19 \pm 0.9^{\mathrm{a}}$ \\
CMB & $55 \pm 0.98^{\mathrm{b}}$ \\
CHL & $105 \pm 1.3^{\mathrm{c}}$ \\
\hline
\end{tabular}

ASP: aspirin, CMB: Cordia africana methanol bark, CHL: Cordia africana Hexane leave. Values with different letters are significantly different at $\mathrm{p}<0.05$.

\section{Antimycobacterial activity}

The MIC values of extracts of $C$. africana against three fast growing Mycobacterium species strains are shown in Table 4. In general there were not major differences in the activity of the extracts. The MIC values range between $256 \mu \mathrm{g} / \mathrm{mL}$ to $1024 \mu \mathrm{g} / \mathrm{mL}$. The methanol extract of the bark of $C$. africana was active against $M$. smegmatis with MIC value of $256 \mu \mathrm{g} / \mathrm{mL}$. Both the methanol extract of the bark and hexane extract of the leave were active against $M$. fortuitum with MIC values of $512 \mu \mathrm{g} / \mathrm{mL}$ in both cases. The hexane extract of the leave was active against M. smegmatis, and M.aurum with MIC value of $1024 \mu \mathrm{g} / \mathrm{mL}$ in both cases. However, the methanol extract of the bark had no activity against M. aurum with MIC value of $>1024 \mu \mathrm{g} / \mathrm{mL}$. Taking into account the cut-off of the antimicrobial activity of plant extracts of $0.1 \mathrm{mg} / \mathrm{mL}$ (Eloff, 2004; Kuete and Efferth, 2010), the antimycobacterial activity of the extracts of C. africana obtained in this study varied from significant to inactive.

Table 4: Minimum inhibitory concentration (MIC in $\mathrm{mg} / \mathrm{mL}$ ) of extracts from hexane leave and methanol bark of Cordia Africana against fast growing mycobacterial strains.

\begin{tabular}{lccc}
\hline \multicolumn{1}{c}{ Extracts } & \multicolumn{3}{c}{ MIC $(\boldsymbol{\mu g} / \mathbf{m l})$} \\
\hline \multicolumn{1}{c}{ CHL } & Ms & $\mathbf{M f}$ & $\mathbf{M a}$ \\
CMB & 1024 & 512 & 1024 \\
& 256 & 512 & $>1024$ \\
Ciprofloxacin & 4 & 8 & 8 \\
Rifampicin & 8 & 2 & 4 \\
\hline
\end{tabular}

CMB: Cordia africana methanol bark, CHL: Cordia africana Hexane leave, M. smegmatis, M. fortuitum, M.aurum 
The MIC values of extracts of $C$. africana against six bacterial species are shown in Table 5 .

Table 5: Minimal inhibitory concentration (MIC in $\mathrm{mg} / \mathrm{mL}$ ) of extracts from hexane leave and methanol bark of Cordia Africana against six bacterial strains

\begin{tabular}{ccccccc}
\hline Extracts & \multicolumn{5}{c}{ MIC $(\boldsymbol{\mu g} / \mathbf{m l})$} \\
\hline CHL & Sa & Ef & BC & Pa & Ec & St \\
CMB & 512 & 256 & 512 & 256 & 512 & 32 \\
Cipro. & 1024 & $>1024$ & $>1024$ & 1024 & 512 & 128 \\
\hline
\end{tabular}

Cipro: ciproxacine, CMB: Cordia africana methanol bark, CHL: Cordia africana Hexane leave, S. aureus, E. faecalis, $B$. cereus, $P$. aeruginosa, E. coli, S. typhimurium

\section{Cytotoxic activity}

Over the past decade a number of in vitro methods have been evaluated with the aim of replacing the mouse bioassay for toxicity testing.Cell culture-based toxicity tests are of interest, having the potential to detect more general cytotoxicity end points. In the present study, the toxicity of two extracts of $C$. africana was evaluated on Vero monkey cells by the MTT assay. The $\mathrm{LC}_{50}$ values obtained was 81.79 and $99.67 \mu \mathrm{g} / \mathrm{mL}$ (Table 6).

Table 6: Cytotoxicity of extracts from of extracts from hexane leave and methanol bark of Cordia africana on Vero monkey kidney cells and their selectivity index (SI) against six bacterial strains

\begin{tabular}{|c|c|c|c|c|c|c|c|}
\hline \multirow[t]{2}{*}{ Extract } & \multirow[t]{2}{*}{$L C_{50}(\mu \mathrm{g} / \mathrm{ml})$} & \multicolumn{6}{|c|}{ Selectivity index ( LC $_{50} /$ MIC) } \\
\hline & & Sa & $E f$ & $B C$ & $P a$ & $E C$ & St \\
\hline $\mathrm{CHL}$ & $81.79 \pm 13.31$ & 0.16 & 0.32 & 0.16 & 0.32 & 0.16 & 2.56 \\
\hline $\begin{array}{l}\text { CMB } \\
\text { DOXO }\end{array}$ & $\begin{array}{l}99.67 \pm 16.10 \\
3.48 \pm 0.45\end{array}$ & $\begin{array}{r}0.10 \\
\text { nd }\end{array}$ & $\begin{array}{r}0.10 \\
n\end{array}$ & 0.10 & 0.10 & $\begin{array}{r}0.19 \\
\text { nd } \quad n \\
\end{array}$ & $\begin{array}{r}0.78 \\
\text { nd }\end{array}$ \\
\hline
\end{tabular}

CMB: Cordia africana methanol bark, CHL: Cordia africana Hexane, Doxo: Doxorubicin, $S$. aureus, E. faecalis, $B$. cereus, $P$. aeruginosa, E. coli, $S$. typhimurium

Table 7: Cytotoxicity of extracts from of extracts from hexane leave and methanol bark of Cordia africana on Vero monkey kidney cells and their selectivity index (SI) against mycobacterial strains

\begin{tabular}{lllll}
\hline Extract & & \multicolumn{3}{c}{ Selectivity index $\left(\mathbf{L C}_{\mathbf{5 0}} / \mathbf{M I C}\right)$} \\
\cline { 3 - 5 } & $\mathbf{L C}_{\mathbf{5 0}}(\boldsymbol{\mu} \mathbf{g} / \mathbf{m l})$ & $\mathbf{M s}$ & $\boldsymbol{M f}$ & $\mathbf{M a}$ \\
\hline CHL & $81.79 \pm 13.31$ & 0.079 & 0.159 & 0.079 \\
CMB & $99.67 \pm 16.10$ & 0.389 & 0.194 & 0.097 \\
DOXO & $3.48 \pm 0.45$ & nd & nd & Nd \\
\hline
\end{tabular}

CMB: Cordia africana methanol bark, CHL: Cordia africana Hexane, Doxo: Doxorubicin, M. smegmatis, M. fortuitum, M.aurum

\section{DISSCUSSION \\ DPPH, ABTS, FRAP, total phenolics (TPC) \\ flavonoids content (TFC)}

It has been reported that the antioxidant activity of plant materials is well correlated with the content of their phenolic compounds (Table 2) (Velioglu et al.,1998). The FRAP and phenolic content of the methanol fruit extract of $C$. africana was previously evaluated and similar results to our findings have been reported (Tewolde-Berhan et al., 2013). The FRAP from the bark extract is higher (93.84) comparable to that found from the bark extract in a similar species Cordia dichotoma bark, with $22.8 \mathrm{mg} \mathrm{mL}-1$ TE on a dry weight basis (Ganjare et al., 2011). The average total phenol values are lower than that reported by (TewoldeBerhan et al., 2013). This could be attributed the part of the plant used and the solvent used in the extraction protocol.

\section{5-Lipoxygenase inhibitory activity}

The observed variability in the degree of inhibition of 15-LOX (Fig 1) by the extracts could be attributed to the differences in their phytochemical composition. The in vitro Lipoxygenase effect of $C$. africana is reported for the first time in this study. The Lipoxygenase products constitute an important class of inflammatory mediators in various inflammatory diseases (Carter et al.,1991), therefore, inhibition of the biosynthesis of inflammatory mediators by blocking the activities of these enzymes would be important for the treatment of many inflammatory disease states (Benrezzouk et al.,1999). It is noteworthy that, the methanol extract of bark of $C$. africana had the highest TPC with good antioxidant activity, a finding which is consistent with Handoussa et al.(2013) who found a relationship between the anti-inflammatory activity and the presence of polyphenols. Antioxidants are also known to inhibit plant Lipoxygenases (Lin et al., 2001). Studies have implicated oxygen free radicals in the process of inflammation and phenolic compounds may block the cascade process of arachidonic acid metabolism by inhibiting lipoxygenase activity, and may serve as ascavenger of reactive free radicals which are produced during arachidonic acid metabolism (Trouillas et al.,2003). 


\section{Antimycobacterial activity}

The antimycobacterial activity of Cordia sinensis has been previously reported (Mariita et al, 2010). To the best of our knowledge this is the first report on the antimycobacterial activity of $C$. african against fast growing Mycobacterium species. It has been reported that, activity against the fast growing Mycobacteriumaurum is highly predictive of activity against Mycobacterium tuberculosis, as the two species have similar drug sensitivity profiles (Chung et al., 1995). Therefore, the significant activity obtained with the methanol extract of the bark of $C$. africana against Mycobacterium aurum in this study may be of interest for further screening against pathogenic Mycobacterium species.

On the bases of criteria of MIC values previously reported by some authors (Eloff, 2004; Kuete and Efferth, 2010), both extracts of C. africana had significant to weak antimicrobial activities, with MIC values ranging between $32 \mu \mathrm{g} / \mathrm{mL}$ to $1024 \mu \mathrm{g} / \mathrm{mL}$. Both the hexane extract of the leave and the methanol extract of the bark of $C$. africana had significant antibacterial activity against $S$. typhimurium with MIC values of $32 \mu \mathrm{g} / \mathrm{mL}$ and $128 \mu \mathrm{g} / \mathrm{mL}$ respectively. The hexane extract of the leave had significant activity against $\mathrm{P}$. aeruginosa and $E$. faecalis with MIC values of $256 \mu \mathrm{g} / \mathrm{mL}$ in both cases and a moderate activity against $S$. aureous and E. coli with MIC values of 512 $\mu \mathrm{g} / \mathrm{mL}$ in both cases. With the exception of $E$. coli with moderate activity of MIC value of $512 \mu \mathrm{g} / \mathrm{mL}$, the methanol extract of the bark of $C$. africana had low activity against $S$. aureous and $\mathrm{P}$. aeruginosa with MIC values of $1024 \mu \mathrm{g} / \mathrm{mL}$ in both cases. However, both $E$. faecalis and $E$. coli were resistant to the methanol extract of the bark with MIC values of more than 1024 $\mu \mathrm{g} / \mathrm{mL}$ in both cases. The antimycobacterial activity of

\section{REFERENCES}

Akinmoladun, A.C., Obuotor, E.M. and Farombi, E.O. (2010). Evaluation of antioxidant and free radical scavenging capacities of some Nigerian indigenous medicinal plants. Journal of Medicinal Food, 13:444-451.

Benrezzouk, R., Terencio, M.C., Ferrádiz, M.L., SanFeliciano, A., Gordaliza, M., Miguel, C.J.M., Puente, M.L. and Alcaraz, M.J. (1999). Inhibition of humans PLA2 and 5-lipoxygenase activities by two neo-clerodanedi terpenoids. Life Science 64: 205-211.

Berker, K.I., Guclu, K., Tor, I. and Apak, R. (2007). Comparative evaluation of Fe (III) reducing power-based antioxidant capacity assays in the presence of phenanthroline, bathophenanthroline, tripyridyltriazine (FRAP), and ferricyanide reagents. Talanta 72, 11571165.

Boik, J. (2001). Natural Compounds in Cancer Therapy. Oregon Medical Press, Princeton, MN, USA.

Brand-Williams, W., Cuvelier, M.E. and Berset, C. (1995). Use of a free radical method to evaluate antioxidant activity. $\angle W T$ - Food Science and Technology, 28: 25-30.
Cordia dichotoma has been previously reported (Kuppasta and Nayak, 2003; Sharker et al 2009). To the best of our knowledge this is the first report on the antimycobacterial activity of $C$. africana.

\section{Cytotoxic activity}

According to the National Cancer Institute (United States) plant screening program, a crude extract is generally considered to have in vitro cytotoxic activity if the $\mathrm{LC}_{50}$ is $<20 \mu \mathrm{g} / \mathrm{mL}$ (Boik, 2001). On the basis of this threshold, all the extracts tested in our study can be considered as safe. This result provides a support on the safety of their traditional use. The methanol extract of bark of $C$. africana had the highest selectivity index (SI) of 2.56 with $S$. typhimurium. In general SI (also called Therapeutic Index) is a measure of potential efficacy versus adverse effects. The higher the selectivity index for a crude extract, the more likely it is that the activity is not due to a general metabolic toxin. An SI >1 for a crude extract increases the likelihood that its toxic and antibacterial compounds are different (Cho-Ngwa et al., 2010). For most of the extract, the SI values were less than 1 due to their poor antimycobacterial activity effect.

\section{CONCLUSION}

In conclusion, $C$. africana extracts investigated have a certain level of 15-lipoxygenase inhibitory and antioxidant activity. The cytotoxicity activity shows that the extract are generally not toxic to vero cells, thus substantiating their safety. This study provides a scientific support for some of the traditional uses. Although it is dangerous to extrapolate from in vitro to in vivo results, the pharmacological activities observed in this study suggests that extracts of this plant species may be effective in human health.

Cai, Y., Luo, Q., Sun, M. and Corke, H. (2004). Antioxidant activity and phenolic compounds of 112 traditional Chinese medicinal plants associated with anticancer. Life Sciences, 74:2157-2184.

Carter, G.W., Young, P.R., Albert, D.H., Bouska, J., Dyer, R., Bell, R.L., Summers, J.B. and Brooks, D.W. (1991). 5-Lipoxygenase inhibitory activity of Zileuton. Journal of Pharmacology and Experimental Therapeutics, 256: 929-937.

Cho-Ngwa,F., Abongwa, M., Ngemenya, M.N. and Nyongbela, K.D. (2010). Selective activity ofextractsof Margaritaria discoidea and Homalium africanum on Onchocercaochengi. BMC Complementary and Alternative Medicine 10: 2010.

Chung, G.A., Aktar, Z., Jackson, S. and Duncan, K., (1995). High-throughput screen for detecting antimycobacterial agents. Antimicrobial agents and chemotherapy, 39: 2235-2238.

Eloff, J.N. (1998). A sensitive and quick microplate method to determine the minimal inhibitory concentration of plant extracts for bacteria. Planta Medica 64: 711-713. 
Bajopas Volume 9 Number 1 June, 2016

Eloff, J.N. (2004). Quantifying the bioactivity of plant extracts during screening and bioassayguided fractionation. Phytomedicine, 11:370371.

Feussner, I. and Wasternack, C. (2002). The Lipoxygenase pathway. Annual Review of Plant Biology, 53: 275-297.

Funk, C. (2006). Lipoxygenase pathways as mediators of early inflammatory events in atherosclerosis. Arteriosclerosis, Thrombosis, and Vascular Biology, 26: 1204-1206.

Ganjare, A.B., Nirmal, S.A., Rub, R.A., Patil, A.N. and Pattan, S.R. (2011). Use of Cordia dichotoma bark in the treatment of ulcerative colitis. Pharmaceutical Biology, 49(8):850-855.

Handoussa, H., Hanafi, R., Eddiasty, I., El-Gendy, M., El-Khatib, A., Linscheid, M., Mahran, L., and Ayoub, N. (2013). Anti-inflammatory and cytotoxic activities of dietary phenolics isolated from Corchorusolitorius and Vitis vinifera. Journal of Functional Foods 5:1204-1216.

Hendra, R., Ahmad, S., Oskoueian, E., Sukari, A. and Shukor, M.Y (2011). Antioxidant, Antiinflammatory and Cytotoxicity of Phaleria macrocarpa (Boerl.) Scheff Fruit. $B M C$ Complement Alternative Medicine, 11:110.

Kuete, V. and Efferth, T., (2010). Cameroonian medicinal plants: pharmacology and derived natural products. Frontiers in Pharmacology 1: 123

Kuppasta, I.J. and Nayak, V. (2003). Anthelmintic activity of fruits of Cordia dichotoma. Indian Journal of Natural Products, 19 (3): 27-29. Abstract.

Lin, J.K., Tsai, S.H. and Lin-Shiau, S.Y. (2001). Antiinflammatory and antitumor effects of flavonoids and flavanoids. Drugs of the Future, 26: $145-157$.

McGaw, L.J., Lall, N., Hlokwe, T.M., Michel, A.L., Meyer, J.J.M. and Eloff, J.N. (2008). Purified compounds and extracts from Euclea species with antimycobacterial activity against Mycobacterium bovis and fast-growing mycobacteria. Biological \& Pharmaceutical Bulletin, 31: 1429-1433.

Mehta, J.L., Rasouli, N., Sinha, A.K. and Molavi, B. (2006).Oxidative stress in diabetes :a mechanistic overview of its effects on atherogenesis and myocardial dysfunction. International Journal of Biochemistry \& Cell Biology, 38:794-803.

Mosmann, T. (1983). Rapid colorimetric assay for cellular growth and survival application to proliferation and cytotoxicity assays. Journal of Immunological Methods, 65:55-63.

Ordonez, A.A.L., Gomez, J.D., Vattuone, M.A. and Isla, M.I. (2006). Antioxidant activities of Sechium edule (Jacq.) Swartz extracts. FoodChemistry, 97:452-458.

Özen, T., Çöllü, Z. and Korkmaz, H. (2010). Antioxidant Properties of Urtica pilulifera Root, Seed, Flower, and Leaf Extract. Journal of Medicinal Food, 13:1224-1231.
Re, R., Pellegrini, N., Proteggente, A., Pannala, A., Yang, M. and Rice-Evans, C. (1999). Antioxidant activity applying an improved ABTS radical cation decolorization assay. Free

Radical Biology and Medicine, 26: 1231-1237.

Reta, R. (2013). Diversity and conservation status of some economically valued indigenous medicinal plants in Hawassa College of Teacher Education Campus, Southern Ethiopia. International Journal of Advanced Research, 1(3): 308-328.

Schmidt, L and Mwaura, L. (2010). Cordia africana Lam. Seed Leaflet No. 147

Sharker, S Md. Pervin, K .and Shahid, Iz. (2009). Analgesic, Antibacterial and Cytotoxic activity of Cordia Dichotoma. Pharmacologyonline, 2: 195-202

Sommer, C. (2005). Inflammation and healing. In: Mattson, C.P.(Ed.), Pathophysiol- ogy, seventhed.Lippincott Williams \&Wilkins, London,UK, pp.387-398.

Talhouk, R., Karam, C., Fostok, S., El-Jouni, W. and Barbour, E. (2007). Anti-inflammatory bioactivities in plant extracts. Journal of Medicinal Food, 10:1-10. Biology, 53: 275297.

Tewolde-Berhan, S., Remberg, S.F., Abegaz, K., Narvhus, J., Abay, F. and Wicklund, T. (2013). Ferric reducing antioxidant power and total phenols in Cordia africana fruit. African Journal of Biochemistry Resaerch, 7(11): 215224.

Thirupathi, K., Sathesh, S.K, Raju V.S., Ravikumar, B., Krishna, D.R., Krishna, G.M. (2008). A Review of Medicinal Plants of the Genus Cordia: Their chemistry and Pharmacological Uses. Journal of Natural Remedies, 8(1): 1 10

Trouillas, P., Calliste, C.A., Allais, D.P., Simon, A., Marfak, A., Delage, C. and Duroux, J.L., (2003). Antioxidant, anti-inflammatory and anti-proliferative properties of sixteen water plant extracts used in the Limousin country side as herbal teas. Food Chemistry, 80: 399407.

Vishwanath, H.S., Anilakumar, K.R., Harsha, S.N., Khanum, F. and Bawa, A.S. (2012). In vitro antioxidant activity of Sesamum indicum seeds. Asian Journal of Pharmaceutical and Clinical Research, 5: 56-60.

Zhang, L., Ravipati, A.S., Koyyalamudi, S.R, Jeong, S.C, Reddy, N., Smith, P.T., Bartlett, J., Shanmugam, K., Münch, D.G. and Wu, M.J: (2011). Antioxidant and Anti-inflammatory Activities of Selected Medicinal Plants Containing Phenolic and Flavonoid compounds. Journal of Agricultural Food Chemistry, 59: 12361-12367.

Zhang, Q., Zhang, J., Shen, J., Silva, A., Dennis, D.A. and Barrow, C.J. (2006). Asimple 96-well microplate method for estimation of total polyphenol content in seaweeds. Journal of Applied Phycology, 18:445-450. 